\title{
Corrigendum: Retrospective study of osteoradionecrosis in the jaws of patients with head and neck cancer
}

\author{
Brena Rodrigues Manzano, Natália Garcia Santaella, Marco Aurélio Oliveira, \\ Cássia Maria Fischer Rubira, Paulo Sérgio da Silva Santos \\ Departament of Surgery, Stomatology, Pathology and Radiology, Bauru School of Dentistry, University of São Paulo, Bauru, Brazil
}

J Korean Assoc Oral Maxillofac Surg 2019;45:21-28

https://doi.org/10.5125/jkaoms.2019.45.1.21

This correction is being published to correct the Tables. In Tables 2-4, corrections are underlined.

In Table 2, there was an overlap of 2 individuals included in "others", which ranged from 12 (8.6\%) to 10 (7.1\%). In Table 3 , 20 other oral cancer patients and 30 other patients with tumors in the head and neck did not present osteoradionecrosis (ORN), and they were added to a total of 139 patients. In Table 4, the incidence of ORN according to each antineoplastic treatment modality in 139 patients, was 10/60 (60.0\%) radiotherapy (RT), 6/32 (18.8\%) RT+chemotherapy (CT)+surgery, 4/30 (13.3\%) $\mathrm{RT}+$ surgery, and $4 / 67$ (5.9\%) RT+CT. The changes in all tables did not change the order of incidence of the factors; thus, the changes clarify the mathematical doubts of readers without invalidating our study.

The authors apologize for any inconvenience this may have caused.

After correction

Table 2. Tumor sites in 139 patients irradiated in the head and neck area

\begin{tabular}{lc}
\hline \multicolumn{1}{c}{ Site } & Value \\
\hline Oropharynx & $53(38.1)$ \\
Oral cavity & $44(31.7)$ \\
Larynx & $20(14.4)$ \\
Hypopharynx & $4(2.9)$ \\
Nasopharynx & $8(5.8)$ \\
Others & $10(7.1)$ \\
\hline
\end{tabular}

${ }^{1}$ Tumors of the parotid, maxillary sinus, skin, brain, thyroid, and hypophysis.

Values are presented as number (\%).

Brena Rodrigues Manzano et al: Retrospective study of osteoradionecrosis in the jaws of patients with head and neck cancer. J Korean Assoc Oral Maxillofac Surg 2019 
Table 3. Incidence of ORN in irradiated $\mathrm{HCN}$ according to tumor location

\begin{tabular}{|c|c|}
\hline Primary tumor & Value \\
\hline \multicolumn{2}{|l|}{ Oral cancer $(n=11)$} \\
\hline Mouthfloor SCC & $7 / 10(70.0)$ \\
\hline Alveolar ridge SCC & $1 / 2(50.0)$ \\
\hline Buccal mucosa SCC & $2 / 7(28.6)$ \\
\hline Palate adenocarcinoma & $1 / 9(11.1)$ \\
\hline Others oral region $^{1}$ & $\underline{0 / 20(0)}$ \\
\hline Skin SCC & $1 / 1(100)$ \\
\hline Oral cancer+oropharynx cancer & $2 / 4(50.0)$ \\
\hline Nasopharynx cancer & $1 / 8(12.5)$ \\
\hline Oropharynx & $5 / 48(10.4)$ \\
\hline Other $^{2}$ & $\underline{0 / 30(0)}$ \\
\hline
\end{tabular}

(ORN: osteoradionecrosis, HCN: head and neck cancer, SCC: squamous cell carcinoma)

${ }^{1}$ Other oral cancer: retromolar. tongue, lower lip.

'Other: breasts, cervical, thyroid, head, hypopharynx, pharynx, larynx. Values are presented as number (ORN/total tumors) (\%).

Brena Rodrigues Manzano et al: Retrospective study of osteoradionecrosis in the jaws of patients with head and neck cancer. J Korean Assoc Oral Maxillofac Surg 2019

Table 4. Incidence of ORN according to antineoplastic treatment

\begin{tabular}{lc}
\hline \multicolumn{1}{c}{ Radiotherapy } & Value \\
\hline Modality & $\underline{6 / 10(60.0)}$ \\
RT & $6 / 32(18.8)$ \\
RT+CT+surgery & $\underline{4 / 30(13.3)}$ \\
RT+surgery & $\underline{4 / 67(5.9)}$ \\
RT+CT & $10 / 54(18.5)$ \\
Type of RT & $8 / 53(15.1)$ \\
Cobalt/conventional & $1 / 14(7.1)$ \\
IMRT & $1 / 18(5.6)$ \\
3D-CRT & Not informed
\end{tabular}

(ORN: osteoradionecrosis, RT: radiotherapy, CT: chemotherapy, IMRT: intensity-modulated radiation therapy, 3D-CRT: threedimensional conformal radiation therapy)

Values are presented as number (ORN/antineoplasic treatment) (\%).

Brena Rodrigues Manzano et al: Retrospective study of osteoradionecrosis in the jaws of patients with head and neck cancer. J Korean Assoc Oral Maxillofac Surg 2019 